\title{
Re-emergent Tongue Tremor as the Presenting Symptom of Parkinson's Disease
}

\author{
Şakir Delil, Feray Bölükbaşı, Naz Yeni, Güneş Kızıltan \\ Department of Neurology, Cerrahpaşa Faculty of Medicine, İstanbul University, İstanbul, Turkey
}

Background: The most common symptom of Parkinson's disease is the unilateral, typically resting tremor in body parts, most commonly in the upper extremities. However, this finding can spread to the other parts of the body like lips, chin, jaw and tongue during the course of the disease. Nevertheless, we have not come across any Parkinson's disease case presenting with tongue tremor in the literature.

Case Report: Here, we present a 58 year-old man with Parkinson's disease presenting with tongue tremor, his striking response to the levodopa test and his follow-up data.
Conclusion: The topography of motor symptoms at onset in Parkinson's disease is presumably determined by the severity of the Lewy body neuronal degeneration in distinct parts of the substantia nigra. Therefore, patterns of somatic symptom progression in Parkinson's disease indicate that involvement of the cranial structures always follows the development of symptoms in the extremities. However, in our case, cranial structures seem to precede the involvement of extremity-related areas.

Keywords: Essential tremor, Parkinson disease, reemergent tongue tremor
Tremor is the most common symptom of Parkinson's disease and the disease frequently presents with this. Most frequently, it appears in the hand, but the unilateral onset of resting tremor in the lower extremity is not rare. During the course of the disease, the tremor may spread to the other side of the body and other body parts such as the lips, chin, jaw and tongue.

Although resting tremor is characteristic of Parkinson's disease, other types of tremor including postural, kinetic and orthostatic tremor may also occur (1). The re-emergent characteristic of the parkinsonian tremor is a key feature which helps to differentiate it from essential tremor (2).

According to our search in the Pubmed search engine for tongue tremor as a presenting feature of Parkinson disease, this has not yet been reported in the literature.

We present here a 58 year-old man whose first manifestation of Parkinson's disease was tongue tremor. The re-emergent feature of the tongue tremor, its association with mild parkin- sonian findings and response to treatment led to the diagnosis of Parkinson's disease.

\section{CASE PRESENTATION}

A 58 year-old male was referred to us upon realising tremor on his tongue, which was intermittent at the beginning and then became continuous. This was his sole complaint.

He had a medical history of hypertension, diabetes mellitus and hypercholesterolemia. His family history was unremarkable. On neurologic examination, there was re-emergent tongue tremor, bradymimia as well as bradykinesia and rigidity in the right upper extremity. Unified Parkinson's Disease Rating Scale (UPDRS) was measured as 13 (sum of part II and part III). His cognitive functions and Standard Mini Mental Test score were within the normal limits. 
His laboratory evaluation, which included the level of ceruloplasmin and copper in the serum, was within normal limits also. Cerebral magnetic resonance imaging (MRI) showed no abnormalities.

Since isolated tongue tremor was formerly reported in patients with essential tremor, there were certain characteristics of our patient that we used to exclude this diagnosis, such as re-emergent feature and associated parkinsonian findings, lack of tremor in any other body part and good response to anti-parkinsonian treatment.

Based on his history and examination, with the diagnosis of Parkinson's disease, the patient was started on pramipexole ( $3 \times 0.125 \mathrm{mg}$ ) and the dose was increased gradually (every 5 days) up to $3 \mathrm{mg} / \mathrm{day}$. At this dose, he noticed some improvement in his tongue tremor. However, since it was still disturbing after 2 months, levodopa $150 \mathrm{mg} /$ day was added to the therapy. With this combination, he reported an approximately $80 \%$ improvement in his complaints. On his follow-up, his neurologic examination was significantly improved and UPDRS score regressed from 13 to 5.

Two years after the diagnosis, during his control visits, his dopaminergic treatment dose was increased upon emergence of tremor in the left arm and there was an overall increase in rigidity as a result of disease progression. His current HoehnYahr Scale is 2. Written and signed informed consent was obtained from the patient for publication of this case report.

\section{DISCUSSION}

Although tongue tremor is not rare in Parkinson's disease, patterns of somatic symptom progression in Parkinson's disease indicate that the involvement of cranial structures always follows the development of symptoms in the extremities (3, 4). Isolated tongue tremor has been reported in patients with essential tremor (5). However, it is usually associated with neck, voice and chin tremor in essential tremor (6). The reemergent feature of tongue tremor in our patient and associated parkinsonian findings, lack of tremor in any other body part and good response to anti-parkinsonian treatment led us to exclude the diagnosis of essential tremor.

It has been proposed that a dominant central generator is responsible for the development of tremor in either orofacial structures or extremities (7). However, the topography of motor symptoms at onset in Parkinson's disease is presumably determined by the severity of the Lewy body neuronal degeneration in distinct parts of the substantia nigra. Involvement of the upper extremities at onset is significantly more frequent in Parkinson's disease, and this finding suggests that the rate of the neuronal degeneration in the region of the substantia nigra corresponding to the upper extremities is more rapid compared to other parts (4) The clinical features of our patient suggest that the involvement of the nigrostriatal system related to the tongue may occasionally precede the involvement of other sub-regions of the substantia nigra.

\section{Ethics Committee Approval: N/A.}

Informed Consent: Written informed consent was obtained from the patient who participated in this study.

Peer-review: Externally peer-reviewed.

Author contributions: Concept - Ş.D., G.K., N.Y.; Design - Ş.D., F.B., G.K.; Supervision - G.K., N.Y.; Resource - Ş.D., F.B.; Materials - Ş.D., G.K.; Data Collection\&/or Processing - Ş.D., F.B., G.K.; Analysis\&/or Interpretation - N.Y., G.K.; Literature Search - Ş.D., F.B.; Writing - Ş.D., F.B., G.K., N.Y.; Critical Reviews - N.Y., G.K.

Conflict of Interest: No conflict of interest was declared by the authors.

Financial Disclosure: The authors declared that this study has received no financial support.

\section{REFERENCES}

1. Sethi KD. Clinical aspects of Parkinson Disease. Curr Opin Neurol 2002; 15:457-60. [CrossRef]

2. Jankovic J, Schwartz KS, Ondo W. Re-emergent tremor of Parkinson's disease. J Neurol Neurosurg Psychiatry 1999;67:646-50. [CrossRef]

3. Dickson JM, Grünewald RA. Somatic symptom progression in idiopathic Parkinson's disease. Parkinsonism Relat Disord 2004;10:487-92. [CrossRef]

4. Damier P, Hirsch EC, Agid Y, Graybiel AM. The substantia nigra of the human brain II. Patterns of loss of dopamine-containing neurons in Parkinson's disease. Brain 1999;122:1437-48. [CrossRef]

5. Biary N, Koller WC. Essential tongue tremor. Mov Disord 1987;2:25-9. [CrossRef]

6. Louis ED, Borden S, Moskowitz CB. Essential tremor centralized brain repository: diagnostic validity and clinical characteristics of a highly selected group of essential tremor cases. Mov Disord 2005;20:1361-5. [CrossRef]

7. Hunker CJ, Abbs JH. Uniform frequency of parkinsonian resting tremor in the lips, jaw, tongue, and index finger. Mov Disord 1990;5:71-7. [CrossRef] 